\title{
3-methylglutaconic aciduria type 1
}

INSERM

\section{Source}

INSERM. (1999). Orphanet: an online rare disease and orphan drug data base. $\underline{3-}$ methylg/utaconic aciduria type 1. ORPHA:67046

3-methylg lutaconic aciduria (3-MGA) type I is an inborn error of leucine metabolism with a variable clinical phenotype ranging from mildly delayed speech to psychomotor retardation, coma, failure to thrive, metabolic acidosis and dystonia. 